\title{
Facilitating the facilitators of action learning in China: practices and prospects
}

\author{
Cheryl Brook \\ University of Portsmouth, Portsmouth, UK \\ Christine Abbott \\ Centre for Action Learning Facilitation, York, UK
}

\begin{abstract}
This paper explores the learning and experience of Western action learning facilitators engaged in developing Chinese facilitators of action learning, all of whom were also managers, as part of a qualification programme based in China. The Western facilitators interviewed for this study had been specifically asked by their hosts to deliver a 'Revans' based approach' to action learning which was to include an emphasis on organisational as well as individual development. This paper suggests that the facilitators interviewed here saw themselves as being and acting very much according to Revans' classical principles. The paper highlights some of the complexities inherent in facilitating action learning in China, and the complex and in some cases contradictory nature of facilitators' learning about their own practice.
\end{abstract}

Key words: Revans' action learning; facilitation; China; culture.

\section{Introduction}

'The Chinese Century' is a neologism coined to suggest that the $21^{\text {st }}$ century will be dominated economically and geopolitically by China in the same way that the $20^{\text {th }}$ century was dominated by America. In developing its trade and industry, China has over the past two decades reached out to the West for management education and development. It has encouraged management development educators to bring their expertise directly to Chinese managers and entrepreneurs (Yolles, lles \& Guo, 2006). This research focuses not on the recipients of such development, but rather on the facilitators of this learning. The principal aim of this paper is to explore facilitators' experiences and learning from implementing action learning programmes in China. In so doing it considers ideas concerning facilitation, current facilitation practices and experiences in relation to what have been termed (mis)representations of Chinese learning preferences (Kennedy, 2002). 
This paper bases its findings on in-depth qualitative interviews with four highly experienced facilitators of action learning who between them have facilitated over 200 action learning participants working in senior roles in state and private industries in Beijing and in other parts of China. We offer observations concerning challenges and issues in the practice of action learning facilitation in China. Whilst the study is limited by its small and very specific sample, and thus no generalisations can be made on the basis of the findings, there are, nonetheless a number of potential implications for practice and for the theory of facilitating action learning. The primary contribution of this paper is to offer some insights into the sense-making generated by Western facilitators of action learning concerning their experiences of working with Chinese managers training to be action learning facilitators. This includes how facilitators perceived apparent differences between Chinese and UK facilitation and practice of action learning, and also how facilitators schooled in the Revans approach dealt with being seen as 'experts' rather than 'facilitators of learning'. The Revans' based approach is understood to be a form of action learning derived from the consistencies in Revans' writings and summarised as Revans' classical principles (RCP) by Pedler, Burgoyne \& Brook (2005). These principles include, amongst others, the requirement for action as the basis for learning; profound personal development resulting from reflection upon action, and working with problems (with no right answers) not puzzles (2005, p. 58).

The principal research objectives to be explored in this paper are to:

- Examine highly experienced action learning facilitators' sense-making of their practice in working with senior managers in Chinese organisations;

- Explore particular challenges and insights arising out of their accounts of their practice;

- Consider approaches to action learning facilitation and how such approaches vary in the light of the Chinese context and culture.

\section{Background to the Research}

The four Western facilitators interviewed for this research had been approached to implement a traditional, Revans-based approach to action learning in part in order to offer a contrast to other action learning models apparently in operation. Some of these models or approaches were said to privilege the facilitator role, limit set member involvement in questioning and insufficiently address the need for organisation-wide learning. The four facilitators had been asked very specifically to focus participants on ways of developing the 
organisation as a whole as well as assisting the development of individual managers. Those interviewed ran a level 5 Institute of Leadership and Management (ILM) certificate in action learning facilitation. The ILM is a UK based management qualifications and training provider and such level 5 qualifications are usually aimed at middle level managers. As part of the qualification, participants' wrote accounts of the kinds of problems action learning was being used to address. These included complex problems such as how to develop management capacity in a high tech start-up and how to improve product quality in a pharmaceutical company. The interviewees ran the facilitators programme with the support of interpreters throughout.

The first cohort was of 24 participants all of whom were senior people and well established in their respective careers. They were a mix of senior consultants, people from state owned and private Chinese businesses and global corporations (for example, major pharmaceutical corporations and banks). The cohort also included two university based academics. None of these managers were under 35 years of age and equal numbers of men and women were represented. Normally the facilitators would run three two day modules but in the case of the work done in China this approach had to be adapted for logistical reasons and for reasons of cost. Consequently, the programme ran in two three day blocks. The translators also stayed in the same hotel as the facilitators and were thus with the facilitators for the majority of the time.

\section{Action learning and the facilitation of action learning sets}

Trehan and Rigg (2013) for example point to the unique position facilitators may be in to help generate knowledge about the organisation or even the wider system within which they are located. They also allude to facilitators acting as co-researchers (in 'insider' or action research terms). Different terms have been applied to the practice - set facilitator, coach, set leader, set adviser and even 'enabler and trusted inquisitor' (Thornton \& Yoong, 2011). Facilitators can and do play a variety of roles, for example co-ordinator, catalyst, guide, critical friend, adviser and coach. The proliferation in practice notwithstanding, as Sanyal (2018) has observed, research on the role of the facilitator of action learning remains 
comparatively limited and research is even less in evidence in the particular context of working with Chinese managers.

In critical action learning the facilitator role involves helping participants' explore taken-forgranted assumptions, emotions and politics associated with the presenting problem; the process lays emphasis upon revealing how power relations are part of action learning. Arguing for this approach Vince (2012) suggests that facilitators and participants have to understand the contradictions that action learning itself generates 'and allow [these contradictions] to inform our practice and enrich it' (2012, p.211). Critical action learning facilitators need to be alive to the insights that are generated through reflection and action and the ways in which learning is 'promoted and prevented in organisations through networks and relations of power' (Vince, 2012, p. 213).

Since Revans offered no definitive single definition of action learning there has been a proliferation of practice, and in consequence widely differing attitudes and ideas concerning the nature of facilitation (Willis, 2004; Marquardt \& Waddill, 2004; Pedler \& Abbott, 2008; Brook, Pedler \& Burgoyne, 2012; Sanyal, 2018). As suggested above, Revans argued that facilitation should be strictly limited to launching the action learning process with some form of limited induction (Revans, 1998, p.12). However, as action learning practice has proliferated, so too have perspectives on the practice of facilitation. Arguments have developed, for example, concerning the need for 'expert' facilitation both in terms of subject matter and in terms of skill as a facilitator (Rigg \& Trehan, 2004: Rigg, 2008). Rigg (2008) has argued for the value to be had in shifting the balance between process and expert facilitation making the case for "bilingualism" in executing the role of facilitator (2008, p. 199). For Rigg, the ultimate value is a facilitator who is skilled enough to combine these twin capabilities becoming able, potentially, to generate and share knowledge across the wider organisation. Conversely, Marquardt (2004) has suggested that the role of the action learning coach is to focus 'solely on the group's learning and not on the problem' and in so doing this will ensure that the group will become more effective 'both in problemsolving abilities and in group interactions' (2004, p. 197). Pedler and Abbott (2013) argue the role of facilitator or set advisor is not merely the facilitation of sets but has two other 
import aspects often neglected that of accoucheur (see below for a discussion of this term) and that of developer of organisational and professional learning.

Action learning is a form of social and experiential learning, being concerned with small groups of peers learning from and with each other through tackling ill-structured problems for which there are no known answers (Revans, 1998; Willis, 2004). Central to Revans' development of the idea of action learning is the notion of 'questioning insight'. For Revans action learning may be differentiated from other kinds of group and experiential learning activities because of the primacy of ' $Q$ ' - which is to say inquiry based on the assumption that no one individual has all the answers or even necessarily the right questions (Willis, 2004). Bandura (1977) stresses that social learning comes from engaging with one's environment and from direct experience; in essence that learning occurs through a process of socialisation and observation. Such learning is not always recognised as such because of its continuous nature and its ubiquity, and because it often constitutes 'tacit' knowledge (Polanyi, 1967). Action learning has the capacity to capture and disseminate such 'tacit' knowledge, and its collaborative, context-sensitive and co-operative nature appears prima facie to be a good fit with Chinese culture and practice (Marquardt, 2015).

A considerable body of literature exists on the nature of facilitation per se and the role of the 'traditional' facilitator. Some of the literature contain elements which the more conventional Revans action learning facilitator may find challenging (Kiser, 1998; Heron, 1999; Hogan, 2002; Rogers, 2010). Heron (1999; 2004) proposes six dimensions of facilitation: planning, meaning, confronting, feeling, structuring and valuing, some of which raise questions for the action learning facilitator. For example, the planning dimension is to do with the aims of the group and how the group acquires its objectives. In classical or conventional action learning the facilitator does not play a great part in this, acting more in the role of accoucheur as Revans himself termed it. The set determines its own objectives, its own curriculum and sets its own ground-rules for set behaviour (Willis, 2004). Wang and Bloodworth (2016) in their account of the first time experience of an action learning facilitator in China make reference to this concept of accoucheur, going on to sum up this aspect of facilitation as clarifying sponsors' and stakeholders' expectations of programme outputs and outcomes prior to project implementation $(2016,177)$. 
Heron's structuring dimension is to do with how the groups' learning is formally structured and is concerned with matters such as topics for learning, resources, and methods. Heron (2004) made it clear that the dimensions could be handled in three different ways; hierarchical, co-operative and autonomous, and that the key for the facilitator was to find a balance between these three approaches. Classical action learners of the kind represented by Willis (2004) would find the hierarchical mode difficult, if not impossible to accept and such a mode would be viewed as 'less like' action learning practice according to her 'action learning continuum' (see Table 1).

The table below contrasts and compares some of Heron's ideas as embodied in the six dimensions of facilitation with some of Willis's indicators of action learning which in their turn were distilled from Revans' original writings. Aside from the potential differences regarding planning and structuring, it is interesting to note the emphasis Revans places on encouraging all set members to develop questioning insight and the concern Revans expressed for egalitarian participation (which latter is open to debate in critical action learning).

\section{Table 1 to be inserted HERE}

Casey (1976) in writing about what was then termed the 'set adviser' was clear that the role was solely to facilitate learning. He writes:

He (sic) is not a teacher in the sense of having a specific area of knowledge to impart but he is a teacher in the sense of helping others to learn. His locus is the Set as a living community and not the projects as technical challenges (Casey, 1976, 164).

Rogers (2010) has proposed that there are eight principles underpinning what she terms 'authentic facilitation'. Amongst these are principles are those which most action learning facilitators would regard as essential, such as focusing on complex 'wicked' problems rather than 'simple' problems (what Revans termed 'puzzles'), focusing on change and also on what Rogers describes as 'authentic, whole-person conversations' $(2010,24)$. Casey (1976) suggests that there are four principal tasks associated with the role, these 
being (i) to facilitate giving, (ii) to facilitate receiving, (iii) to clarify the various processes of action leaning and (iv) to help other take over the first three tasks $(1976,166)$. This notwithstanding, the role of facilitation is seen differently by different action learning practitioners. Critical action learning practitioners put more emphasis upon the role of an expert facilitator and this contrasts with Revans' expressed scepticism toward experts of all sorts, including the idea of a long-term action learning facilitator in particular (Revans, 2011; Brook, Pedler \& Burgoyne, 2012).

Willis (2004) as indicated above proposes that action learners need to uphold a Revans' "gold standard" based on a distillation of 23 critical markers of action learning derived from Revans' writings over a 50 year period. Willis posits a continuum of action learning practice, from practices which are "less like" action learning (including some critical action learning practices, such as ongoing facilitation and expert input) to practices which are "more like" action learning in that they promote self-organising and evolutionary features and adhere to the 23 critical markers $(2004,15-18)$. Referring to Revans' view that theory should be kept to a minimum, Pedler and Burgoyne caution that: "action learning can benefit from critical thinking, but only if this is offered in the spirit of peer inquiry and in the context of a mutual striving for useful action. It is the assumed superiority and hegemony of theory and theorists over practice and practitioners that is rejected, not the value of critical thinking" (2008, p. 332). Some American models of action learning lay great stress on the role of the action learning coach (Marquardt, 2004; Marsick, 2007). This model has a strong presence in China, and is a form in which the coach may take on the questioning role to a greater degree than set members.

As Coughlan and Couglan (2011) have demonstrated, action learning offers the potential to generate learning in (and also between) organisations and this in its turn requires that action learning be seen as a learning mechanism. In striving to achieve a network action learning approach facilitators can encourage the development and use of structural learning mechanisms. Coughlan and Coghlan (2011) give examples such as post project reviews, databases, and intranets. Vince (2004) argues that learning does not just occur though an individual's own experience but through engaging with and collectively reflecting upon organisational power relations. In his view organisational learning should be an aim of 
action learning. This also aligns with Rigg (2008) who makes a point about the importance of the collective, in her case especially in a public services context. In that particular context she suggests that: 'individual development for its own sake is a luxury. The focus has to be on the organisation if not the wider system' (2008, p.187).

\section{Culture and the Importation of Management Learning}

Burger and Trehan (2018) in writing about the transference of action learning into an East African context consider the implications of action learning itself as a cultural product. They suggest that the specific context into which action learning is being transposed is often ignored and yet requires serious attention; for example by considering indigenous pedagogic practices which shape expectations. Their work has resonance, even though it deals with an entirely different cultural context. Burger and Trehan (2018) allude to the idea that educational practices in East Africa often place the teacher centre-stage as a deliverer of incontestable 'truths'. Mughal, Gattrell and Stead (2017) point to a comparable view of the teacher in Pakistani culture. And a similar picture emerges in some of the literature about Chinese educational practice wherein the teacher is viewed as a highly respected, yet largely unchallengeable authority figure.

Much has been written about the Chinese learner (though usually about students rather than managers) their highly developed respect for teachers, preference for memorisation and rote learning, and their apparent distaste for group learning. But in the last two decades counter arguments and evidence has been assembled (Kennedy, 2002; Nguyen, Terlouw \& Pilot, 2006). The still widely referenced Hofstede (1980) framework for measuring cultural difference consists in part of the key dimensions of cultural difference 'individuality / collectivism' and 'power / distance' and these dimensions are often referenced to explain some apparent key differences between learners in the UK and learners in China. There is a danger of over generalisation and simplification in adhering uncritically to such a framework. In relation to group work, for example, Kennedy (2002) suggests that the dominant 'picture of a passive, non-participative Chinese learner' may be a misinterpretation of a more 'reflective' character, and Nguyen, et al. (2006) asserts that learners from CHC (Confucian Heritage Culture) backgrounds positively prefer working in groups and, indeed, even perform better in groups than individually. 
Fan (1998) has written about the apparent problems of importing management 'know-how' from the West to the East, and the related question as to whether or not management know-how is universal or culture-bound (1998, p. 201). Similarly Lamb and Currie (2011) have considered issues concerning the necessity (or otherwise) of adapting (in their case example) the MBA model to suit Chinese social norms. The suggestion has been made that the US MBA is a particular cultural entity and that its importation into Chinese society can cause tensions and ambiguities not least because it may run counter to Confucian ideas of social harmony and order (Sturdy and Gabriel, 2000 quoted by Lamb and Currie, 2011). Action learning is said to be a context sensitive method especially as the 'curriculum' is determined by set members themselves. This may in part account for the relative ease with which it has been accepted as a development practice for senior managers in China. But there are other factors which need to be considered and which may help to explain why the action learning method has found a measure of acceptance.

Marquardt (2015) has made some interesting points about the 'fit' between action learning and Chinese culture. He suggests that one of the reasons for its apparently successful adoption is that Confucius, and subsequent philosophers in the Confucian mould such as Zisi, have 'defined and described learning in very 'action learning-like' terms' (2015, p. 325). He quotes the latter as developing five key factors of learning which include terms such as insightful questioning, critically reflective thinking, debate and action, and cites also Yangming who believed that 'knowing' and 'doing' were one and the same. As Marquardt (2015) concludes, such prescriptions come remarkably close to Revans' 'characteristic assumptions' of action learning.

\section{Methodology}

This is a small scale qualitative study rooted in an interpretivist framework. Semi structured interviews were conducted with four highly experienced Western action learning facilitators who all have significant experience of working with senior managers in China. The semistructured interview is a method of data collection often used in qualitative research in which the interviewer asks about a set of themes using some predetermined questions. As 
Saunders \& Lewis (2012) suggest, with this method the interviewer 'may choose to omit some topics and questions and ask additional questions as appropriate' which allows considerable flexibility of approach (2012, p. 151). Braun \& Clarke (2006) define the approach in similar terms commenting on 'the scope for the participants to raise issues that the researcher has not anticipated' (2013, p. 78). These interviews ranged between 60 and 90 minutes in length. The authors transcribed these and subjected the transcripts to thematic analysis (Braun \& Clarke, 2013). Another advantage of semi-structured interviews is that they help to generate rapport and empathy, and offer time in which to elicit rich, deep and interesting data (Smith, Flowers, and Larkin, 2009).

Although the sample size is very small which means, of course, that findings cannot be generalised, the data does offer some rich insights into the perspectives of highly experienced action learning facilitators working in this very specific context. The interviews were recorded with the permission of the participants in line with the ethical guidelines of the university (Smith, Flowers, and Larkin 2009). Verbatim transcriptions of the interviews were subsequently analysed by the researchers, independently in the first instance to identify the key themes (Grbich 2007). Both researchers undertook a review of the themes An alphanumeric is used to preserve anonymity.

We broadly followed the stages of coding outlined by Braun \& Clarke (2013). The stages they outline for thematic analysis include reading and familiarisation with the transcripts, initial coding across the data set, searching for themes, reviewing the themes, defining and naming themes and finalising analysis. Themes which emerged from this process included the role of the facilitator, the nature of beliefs and ideas about facilitation, differences between Chinese and UK facilitation of action learning and issues around expert power. Not all of these issues are reflected in the extant literature. Draft interview notes were sent to the interviewees to ensure that they were an accurate representation of each conversation (Creswell \& Poth, 2018). Examples of some 'core' questions asked at interview are given below. As these were semi-structured interviews other probing and follow-up questions particular to the individuals being interviewed were also posed but do not feature in the list below. 


\section{Table 2 to be inserted HERE}

\section{Findings and Discussion}

\section{The Role of the Facilitator}

The facilitators interviewed for this study saw themselves as being and acting very much in the Revans' mould, especially in viewing the role of facilitator as fundamentally temporary. As suggested above, the role of the accoucheur (a term Revans used for the role; it literally means 'male midwife') was to 'speed the integration of the set...so that it achieves independence at the earliest possible moment' $(1998,10)$. Thus, one interviewee argues that they see their primary obligation as 'setting the group alight; getting them going':

Like Casey sees it, I see it as helping people to listen to each other, to give, receive from each other, understanding the processes of group-work. Helping them to do it for themselves; modelling it for them and getting the conditions right. I like to withdraw from the group in my practice (the Revans' approach) when I can (F1)

Another facilitator referenced both Casey and Rogers, as well as Revans, as being influential in their practice of action learning facilitation, especially in terms of the more 'learner centred' approach which gives full scope to Revans' notion of 'comrades in adversity' learning from and with each other. Such a practice is closer to Willis's 'gold standard in being less interventionist, less directive and more short-term in nature. The facilitator was increasingly of the view that:

You can't learn anything significant by being taught...Revans' suspicion or demotion of the role (of facilitator) to that of 'supernumerary' as he calls it fits with that view. (F2)

The extent and manner in which facilitators intervene with a set can also be problematic. As Vince (2012) has suggested 'it can be difficult for us to recognize the harm our 'helpfulness' might cause for others. We may well believe that we are empowering others when we are in fact controlling, restricting, or undermining them' $(2012,215)$. One interviewee commented on this kind of balancing act thus: 'we (as facilitators) have to work out how we can support them without taking the responsibility away from the team' (F4). 
The facilitators felt that the role and the practice had to have impact in and across the organisation as a whole, not just showing impact at the level of the individual or even the set. Again this chimes with Revans' own view of the practice in which set members work on problems which carry 'significant risk of penalty for failure' $(1998$, p. 8) which indicates the level of importance attached to them. The difficulty lies in how to go about achieving this wider impact.
A key part of the role is the organisational learning role; how do you generalise the benefits from what a set has produced? How do you get it into a space where more people can learn from it, and where you can get into a dialogue with the members of the set and the people who are in another part of the organisation or who are responsible for other functions? (F2)

This focus on the need for organisational-wide benefit is apparent in the facilitators' views of their role in this context. One way of attempting to address this was to explicitly ask set members what they are learning about the organisation and how they intend to take learning forward into the organisation. This was built into the 'reflection and review' part of the set meeting. Coughlan and Coghlan's (2011) ideas concerning structural learning mechanisms also have resonance here.

In China one of the things that was missing from the version of action learning they had been working with was to do with achieving organisational learning and that is one of the hardest things to do - to recognise the learning for the organisation and feed that back into the system. And I think the Chinese groups found that organisational learning part the hardest part - especially finding ways of getting the organisation to accept the learning. But I don't think that's unique to China (F1)

This emphasis on organisational learning was alluded to by all four interviewees, along with its corollary, the difficulties of sharing knowledge across the organisation. However, one interviewee 'coming from a background in person centred-ness, and allowing the person to become the expert of their own lives' (F3) did express the need for balance between individual and organisational development. In doing so the interviewee talked about the need to provide 'just enough support', whilst acknowledging that that the amount of support given would change over time as the group gradually took on more responsibility 
for the life of the set. The same interviewee went on to suggest that the emphasis on the collective in China did present problems in terms of individual development.

They struggle with the idea of ' $\mathrm{l}$ ' and the ' $w e$ '; the boundaries between the ' $\mathrm{l}$ ' and the 'we' become more blurred - it becomes all about the collective good of the organisation (F3).

The Western problem of the often too individualistic a focus of action learning was thus less of an apparent issue in this context (Vince, 2004). The practice of Chinese action learners working in their sets but in one room was seen as helpful in relation to exchange of knowledge and ideas. This preference (despite noise levels and other distractions) is similar in form to the idea of network action learning in a conference setting termed the 'knowledge fusion method' (Flowers \& Reeve, 2002). This approach was a 'whole group' action learning approach which differed by including a blended, virtual aspect $(2002,31)$.

\section{Differences between Chinese and UK facilitation and action learning}

Kennedy (2002) has suggested that some of the received wisdom concerning the adult Chinese learner has been overplayed, and his scepticism is borne out in many of the views expressed by the interviewees. Yet some cultural differences between individualist and collectivist approaches were surfaced. One interviewee spoke about an apparent need for clear rules of engagement which needed to be visible throughout, and also a difficulty in encouraging in-set challenge (especially questioning):

They needed a clear methodology - a step-by-step guide... there's a politeness in the

culture that can sometimes prevent too much challenge. It's not fixed in their culture to think too much 'out of the box' (F4).

This issue of addressing difficulties in challenging and questioning is something Brook \& Milner (2014) discuss; part of their practice is to encourage participants to share and discuss their experiences of learning at school or university early on in the life of the set, and to consider some of the implications of these experiences as a lead-in to developing questioning skills.

The preference for groups and physically being with large numbers of others was a stark difference for the interviewees between Chinese and Western practice.

One comments: 
The Chinese like to be in groups in the same room. They find it quite hard to be independent. They like to be in teams. They like to be with other people, in the true sense of 'being'. They physically like to be with other people, and find it hard to be an independent voice. I try to help them to be...to find that independent voice (F1)

Action learning sets traditionally operate in groups of no more than six. Whilst there was no problem in getting people to work in groups of that number, nonetheless they insisted on all being present in one room.

The really unusual thing was that all 6 sets would operate at the same time in the same room in different sets and at 6 different tables; they would not go into separate rooms. And the noise level was unbearable for me at times. But this is a very noisy culture - it's the same in restaurants where you can't hear yourself speak (F1)

There is still a debate in the literature concerning the focus of action learning, and some concerns expressed regarding an apparent over-emphasis on individual / personal problem solving at the expense of organisational problem solving (Vince, 2004; Rigg, 2006; Brook, Pedler \& Burgoyne, 2012). The findings from this research indicate that whilst Chinese managers have no qualms about sharing personal issues as part of set discussions, their focus is firmly on organisational and business problems. For example:

They prefer to work as a team; it's all about the collective. So for example, the team from Company $X$ would work on recruitment, the team from $x$ would work on strategy, the team from $y$ on the problem we've got with packaging. They all accept that they have individual roles within that. They certainly wouldn't do an immediate individual problem, which does often happen in the UK, say a manager coming in with an urgent disciplinary problem with a member of staff. They stick with the team effort and this makes the organisational learning much easier. And they really cared about their issue; they really want to do something about it (F1).

The facilitator in this case did not expect the levels of personal disclosure which actually came about as part of the set work, nor how animated and lacking in self-consciousness Chinese managers would be in enacting or describing issues in the set. This was echoed by other interviewees: 
And they would be adventurous (again not one of my expectations of them) and they are not at all a self-conscious people, and they would go into constellations and using other people in the group to act out scenes, and they would use the flip chart and so on. No self-consciousness whatsoever. They would stand on tables and lie on the floor to make their points (F1)

The facilitator in this case, also felt she learned a great deal about herself and how she could develop her own facilitation skills. But also she felt she was able to observe and interpret power relations in a much 'cleaner' way without the moderating effects of language: 'And you can only intervene if they want you to and ask the translator... The principal change for me is that I learned to wait to be invited to participate. I had to wait to be invited to speak. And it's a powerful lesson.' (F1). This also fits with Revans' view about where power should lie in conventional action learning; that the set should operate, as far as practicable, in an egalitarian manner with the facilitator guiding rather than leading. Moreover, the facilitator in this case found that her own capacity for observation was sharpened by the experience: 'because there's no language getting in the way of what you see, you see who is looking at whom; you see the body language and who's talking more, who's talking less, who's using power.' (F1). In this experience we see the facilitator experiencing action learning as Abbott and Taylor $(2013,44)$ describe it 'liberating, freeing us from established ways of doing through a new way of working'.

\section{The seductiveness of expert power}

Revans had firm views about the place of expertise in relation to the practice of action learning, and herein lies another concern for facilitators of action learning schooled in the Revans approach. Revans regarded such 'expert' interventions in action learning as 'ambiguous, in general opinionative, and at worst, reactionary' $(1998,10)$. Because of the facilitators' expertise in action learning, they found themselves being asked 'are we doing it right?' almost continuously. One respondent argued that this was only to be expected, and a perfectly natural response. In writing about this very concern, Pedler and Abbott (2008) have observed that part of the anxiety emerges from the very demanding nature of the action learning facilitators' role. 'These demands stem from the nature of participant expectations, the skill requirements of the job and the choice of role models or orientations in this work' $(2008,196)$. Heron $(2004)$ has made the point that individual facilitator style 
and approach will reflect values held about development and learning. Those schooled in a Revans approach will value self-direction, autonomy and the privileging of questioning insight. One of the interviewees said that despite feeling overwhelmed by the learners 'demanding right answers' and 'treating you like an expert':

'...when they really got going on action learning they seemed to get it and separate that out; they got the idea of facilitation. They seemed to do this apparently quite easily. 'You're a teacher now; now you're a facilitator' (F1)

A key anxiety in this respect was the concern that having been positioned as having 'brought Revans' ideas to China', would the facilitator be able to be true to those ideas and principles?

My big worry was about introducing Revans' ideas about action learning. My question always was - am I being true to those ideas? Am I tailoring it in a way that will dilute it, which is after all why I'm here? I was always anxious about that. Am I doing that faithfully? Am I in any way watering it down? (F1).

This was partly reconciled by bringing Willis's 23 markers of Revans 'gold standard', placing the markers on cards and positioning them round the room so that participants always had sight of them as guides. These included such principles as: is easily differentiated from other kinds of small group activities by virtue of the dominance of ' $Q$ ' (i.e., inquiry based on the assumption that no one has the answers or even the right questions) and excludes all 'fabrications of reality' and insists on working with the real thing in the real world (Willis, 2004, pp17-18). As the facilitator remarked: 'I found They really liked having those rules there, and yet they did feel quite comfortable disregarding them too if they felt they needed to do that.' (F1). All the interviewees commented on ways in which their participants made their practice more 'Chinese'. The facilitators reported little difficulty in appreciating the underlying philosophy of action learning. One remarked:

They got Revans. In fact I recall one person asking if Revans was Chinese because when he looked at Willis's rules they thought this was very akin to Confucian philosophy (F1).

\section{Conclusion}

This paper aimed to examine experienced facilitators' experiences and sense-making concerning their practice in developing Chinese facilitators of action learning. It makes a 
contribution to the extant literature by offering some insights on the role and practice of the action learning facilitator, especially in a Chinese context. There is a considerable body of literature now on the various forms of action learning, what is being learned through action learning and its applications. However, research work on the role of the action learning facilitator (especially in a Chinese context) appears to be limited ( $\mathrm{O}^{\prime} \mathrm{Neil}$ and Marsick 2014; Sanyal, 2018).

What are the possible implications of this study for action learning practitioners' facilitating sets and practising globally? The study underscores the complexities and contradictions inherent in facilitating action learning - the tension, for example, between the original conception Revans had of the role as accoucheur, and the needs and learning preferences of participants schooled in a more authoritarian teacher-led environment. That notwithstanding, the evidence from this small sample of experienced facilitators is that the protean nature of action learning means that participants have little difficulty in making the practice assume Chinese characteristics. As a context sensitive method action learning has not historically been seen as 'culturally bound', although Mughal, Gatrell and Stead (2017) and Burger and Trehan (2018) call that assumption into question. In an answer to this conundrum Mughal et al. (2017) suggest that the facilitator needs to share responsibility with set members in surfacing and developing awareness of beliefs, practices and behaviours.

Perhaps another reason why action learning is adaptable lies in the fact that its practice is so varied, yet there remains widespread agreement as to the core features. One possibility is that the Chinese action learning facilitator and set member may find themselves more in tune with Revans' original conception of action learning than some Western managers who struggle with a method that lacks an imposed curriculum. Burger and Trehan's (2018) thesis has merit in suggesting that there is much to be gained from examining the idea of the culturally sensitive in action learning and in attending to the specific context by, for example, acknowledging and understanding the nature and impact of indigenous pedagogical practices. 
However, the image of the passive, non-participatory, 'teacher' dominated learning environment is not wholly borne out by these facilitators' experiences. Questioning comes easily, and the learners are actively and unselfconsciously engaged. As Kennedy (2002) has suggested, the Chinese learning style is more complex than indicated by some Western interpretations.

To the extent that the Chinese facilitator or set member is more oriented toward the collective, there is evidence from this study that whilst personal disclosure and personal development occur the focus is firmly on organisational-wide problems. This preference sits well with many Western practitioners' views of action learning practice where there has been some movement away from what was perceived as an old individualistic focus of action learning (Vince, 2004).

A key requirement of the programme was for action learning to aid organisational learning. The preference for many sets working in one room may aid networking and shared learning across organisations. There is also an apparent preference for rules or at least access to rules in Chinese action learning practice, though Chinese action learners felt free to abandon certain rules once they felt they had grasped the essential idea of action learning. Willis's (2004) 23 indicators thus found ready acceptance. This paper has therefore attempted to highlight some of the complexities inherent in facilitating action learning, but also the complex and in some cases contradictory nature of facilitators' learning about their own practice. 


\section{References}

Abbott, C. \& Taylor P. 2013. Action Learning in Social Work London: Sage

Bandura, A. 1977. Social Learning Theory. Englewood Cliffs; London: Prentice-Hall.

Burger, U. \& Trehan. K. 2018. Action Learning in East Africa: New Encounters or Impossible Challenges. Action Learning: Research and Practice. 15(2) 126-138.

Brook, C., Pedler, M. \& Burgoyne, J. 2012. Some debates and challenges in the literature on action learning: the state of the art since Revans. Human Resource Development International, 15 (3), pp. 269-282.

Brook, C. \& Milner, C. 2014. 'I have no English friends': some observations on the practice of action learning with international business students. 11:2, 225-232.

Casey, D. 1976. The role of the Set Adviser in Pedler, M. (Ed). Action Learning in Practice. $4^{\text {th }}$ Ed. Farnham: Gower Publishing.

Coughlan, P., and D. Coghlan. 2011. Collaborative Improvement Through Network Action Learning. Cheltenham: Edward Elgar

Creswell, J.W. and Poth, C.N. 2018. Qualitative Inquiry and Research Design Choosing among Five Approaches. 4th Edition, SAGE Publications, Inc., Thousand Oaks.

Grbich, C. 2007. Qualitative Data Analysis: An Introduction. London: Sage.

Fan, Y. 1998. The Transfer of Western Management to China: Context, Content and Constraints. Management Learning. 29 (2) 201:221.

Heron, J. 2004. The Complete Facilitator's Handbook. London: Kogan-Page.

Kennedy, P. 2002. Learning cultures and learning styles: myth-understandings about adult (Hong Kong) Chinese learners. International Journal of Lifelong Education, 21(5), pp 430445.

Marquardt, M. 2004. Optimizing the power of Action Learning: Solving Problems and Building Leaders in Real Time. California: Davies-Black.

Marquardt, M. \& Waddill, D. 2004. The power of learning in action learning: a conceptual analysis of how the five schools of adult learning theories are incorporated within the practice of action learning, Action Learning: Research and Practice, 1:2, 185-202.

Marquardt, M. 2015. Action Learning in China. Action Learning: Research and Practice. 12 (3) 325-333.

Mughal, F., Gatrell, C. \& Stead, V. 2018. Cultural politics and the role of the action learning facilitator: Analysing the negotiation of critical action learning in the Pakistani MBA through a Bourdieusain lens. Management Learning. 49(1). 69-85.

O’Neil, J. \& Marsick, V. 2007. Understanding Action Learning. New York: Amacom. 
O’Neil, J., and V. J. Marsick. 2014. "ActionLearning Coaching." Advances in Developing HumanResources16 (2): 202-221

Pedler, M. \& Abbott, C. 2008. Am I doing it right? Facilitating action learning for service improvement. Leadership in Health Services. 21(3) pp.185-199

Pedler, M. \& Abbott, C. 2008. Facilitating Action Learning: A practitioners Guide.

Maidenhead McGraw Hill

Polanyi, M. 1967. The Tacit Dimension. New York, Doubleday.

Nguyen, P-M., Terlouw, C., \& Pilot, A. 2006. Culturally appropriate pedagogy: the case of group learning in Confucian heritage culture context. Intercultural Education, 17(1) pp1-19.

Revans, R. 1998. The ABC of Action Learning. London: Lemos \& Crane.

Rigg, C., Trehan, K. 2004. Reflections on Working with Critical Action Learning. Action Learning: Research and Practice. 1, 2, p. 149 - 165.

Rigg, C. \& Richards, S. 2006. Action learning, leadership and organisational development in public services. London: Routledge.

Rigg, C. 2008. Action learning for organizational and systemic development: towards a 'both-and' understanding of ' $\mathrm{I}$ ' and 'we'. Action Learning: Research and Practice 5:2, pp 105116.

Rogers, J. 2010. Facilitating Groups. Maidenhead: McGraw-Hill.

Sanyal, C. 2018. Learning, action and solutions in action learning: investigation of facilitation practice using the concept of living theories. Action Learning: Research and Practice, 15:1, 317.

Saunders, M. \& Lewis, P. (2012). Doing Research in Business \& Management: An Essential Guide to Planning Your Project. Essex: Pearson.

Sturdy, A. \& Gabriel, Y. 2000. Missionaries, Mercenaries or Car Salesmen? MBA Teaching in Malaysia. Journal of Management Studies 37:7 pp 979-1002.

Thornton, K., \& Yoong, P. 2011. The Role of the Blended Action Learning Facilitator: An Enabler of Learning and a Trusted Inquisitor. Action Learning: Research and Practice. 8(2): 129-146.

Vince, R. 2012. The contradictions of impact: action learning and power in organizations, Action Learning: Research and Practice, 9:3, 209-218.

Vince, R. (2004). Action learning and organisational learning: power, politics, and emotion in organisations. Action Learning: Research and Practice, 1. 63-78.

Wang, J. \& Bloodworth, M. 2016. First time facilitator's experience: designing and facilitating an action learning programme in China. Action Learning: Research and Practice, 13(2). 176-183.

Willis, V. 2004. Inspecting cases against Revans' 'gold standard' of action learning. Action Learning: Research and Practice, 1:1, 11-27.

Yolles, M.,lles, P. \& Guo, K. 2006. Culture and transformational change with China's accession to the WTO. Journal of Technology Management in China. 1(2) pp147-158. 
Table 1 to be inserted on page 6

Table 1: Aspects of Heron's (2004) dimensions compared and contrasted with aspects of Willis's (2004) indicators of action learning

\begin{tabular}{|l|l|}
\hline Heron's Dimensions 2004, p6. & Willis's markers 2004, p15. \\
\hline $\begin{array}{l}\text { Planning dimension - goal oriented 'ends and } \\
\text { means' and aims of the group. }\end{array}$ & $\begin{array}{l}\text { Action learning has singular, explicit and } \\
\text { undiluted purpose but is set by set self- } \\
\text { organising }\end{array}$ \\
\hline $\begin{array}{l}\text { Meaning dimension - participants' making } \\
\text { sense of experience; reasons for doing things } \\
\text { and reactions. }\end{array}$ & $\begin{array}{l}\text { 'P' - programmed instruction exists in and is } \\
\text { the province of the set and learners } \\
\text { themselves; action learning demands } \\
\text { intellectual and personal honesty }\end{array}$ \\
\hline $\begin{array}{l}\text { The confronting dimension - challenge and } \\
\text { consciousness raising about resistances and } \\
\text { avoidances for example. }\end{array}$ & $\begin{array}{l}\text { Q (questioning insight) dominates and is } \\
\text { privileged over programmed instruction }\end{array}$ \\
\hline $\begin{array}{l}\text { Feeling dimension - management of feelings } \\
\text { and emotion. }\end{array}$ & $\begin{array}{l}\text { Action learning requires self-observation, } \\
\text { unvarnished reflection \& willingness to adopt } \\
\text { change in perspective and behaviour }\end{array}$ \\
\hline $\begin{array}{l}\text { Structuring dimension - methods of learning; } \\
\text { form of learning. }\end{array}$ & $\begin{array}{l}\text { Finds formal instruction irrelevant for its } \\
\text { purposes; locates social learning in exchanges }\end{array}$ \\
\hline $\begin{array}{l}\text { Valuing dimension - creating a supportive } \\
\text { climate; empowering individuals. }\end{array}$ & $\begin{array}{l}\text { Comrades in adversity; values egalitarian } \\
\text { participation }\end{array}$ \\
\hline
\end{tabular}

\section{Table 2 to be inserted on $p 11$}

\section{Table 2 ‘Core’ Interview Questions}

How did you first become involved in action learning work in China?

What is your view of the role of the facilitator?

What do you see as the principal skills of the facilitator, especially in this context?

Does the Chinese practice of action learning differ from Western practice? If so, how?

Is there any difference between action learning facilitation and other kinds of facilitation?

Did you find that any of Confucian values (for example, harmonious group working, not questioning teachers, maintaining 'face') impacted upon your training of action learning facilitators? If so, in what ways? 